\title{
Gestational gigantomastia complicated with deep vein thrombosis
}

\author{
A Kaluarachchi', M R M Rishard', A K P Ranaweera ${ }^{1}$, T Beneragama ${ }^{2}$, M V C de Silva ${ }^{1}$ (Index \\ words: gestational, gigantomastia, deep vein thrombosis, breast, pregnancy)
}

Ceylon Medical Journal 2018; 63: 84-85

DOI: http://doi.org/10.4038/cmj.v63i2.8682

\section{Introduction}

Gestational gigantomastia is a rare complication in pregnancy occurring in 1:28,000 to $1: 11,8000$ pregnancies [1]. The first case was reported by Palmuth in 1968 [1]. Gestational gigantomastia usually affects both breasts but rarely it can be unilateral [2]. It is known to resolve to near pre-pregnancy size following delivery however, could persist beyond pregnancy [1]. There is a 93\% chance of recurrence in a subsequent pregnancy [1].

\section{Case report}

A 34 year woman in her third pregnancy presented at period of gestation of 20 weeks with progressive bilateral diffuse enlargement of breasts since 11 weeks of period of gestation (Figure 1). She also complained of left sided leg swelling of two weeks duration. Ultrasound of the breast showed large lobulated bilateral breast masses with increased vascularity. Doppler studies of the legs confirmed the presence of deep vein thrombosis of the left leg extending up to the external iliac vein. Hormone profile and thrombophilia screening was normal.

She was commenced on bromocriptine and low molecular weight heparin. Despite the medical management there was progressive breast enlargement with ulceration and sepsis. Because of this, bilateral total mastectomy including removal of axillary tails was performed at 24 weeks. (Figure 2). The right breast and axillary tail weighed $5.5 \mathrm{~kg}$ and $2.2 \mathrm{~kg}$ respectively. The left breast and axillary tail weighed $6.6 \mathrm{~kg}$ and $2.1 \mathrm{~kg}$ respectively. Histology confirmed gestational gigantomastia. Pregnancy was continued till term. She delivered a $2.6 \mathrm{~kg}$ baby girl vaginally at 37 weeks of gestation.

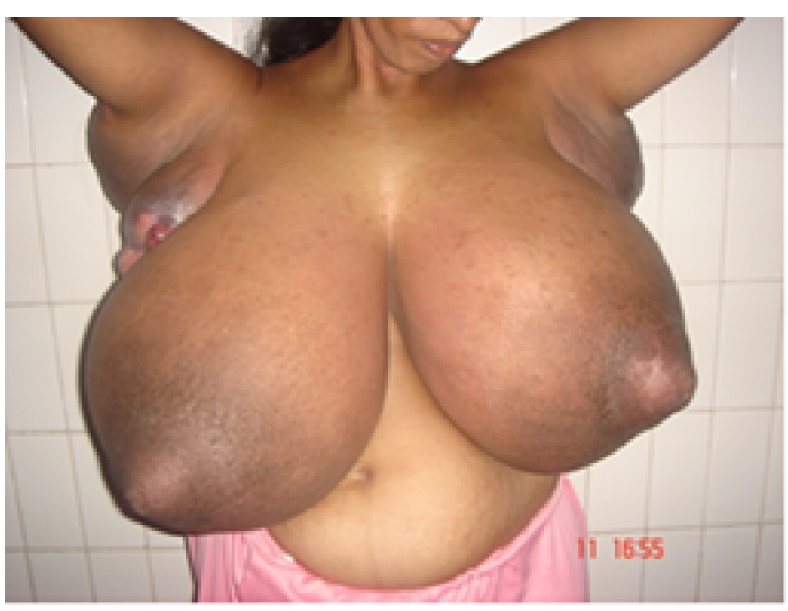

Figure 1. Gigantomastia with ulcerated axillary.

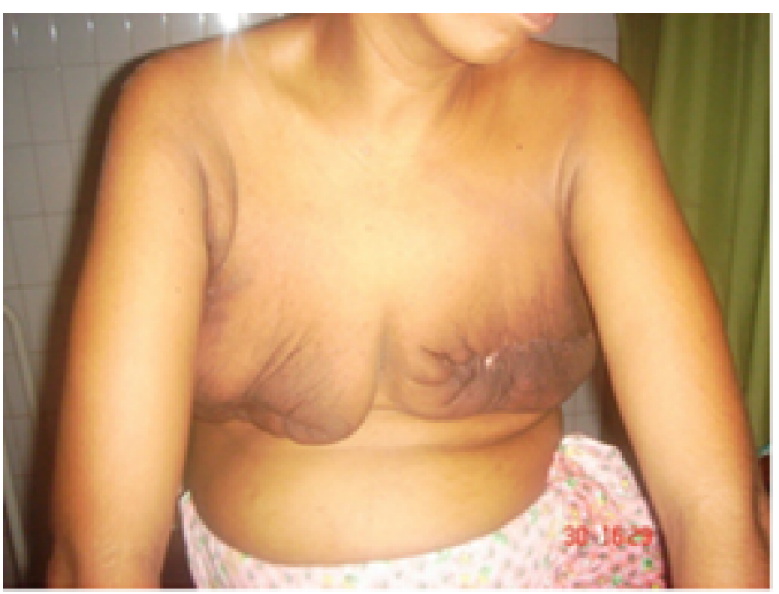

Figure 2. After the mastectomy.

${ }^{1}$ Department of Obstetrics and Gynaecology, Faculty of Medicine, University of Colombo, Sri Lanka, ${ }^{2}$ National Hospital of Sri Lanka, Colombo, Sri Lanka.

Correspondence: AK, e-mail: <athula.kal@gmail.com>. Received 22 May 2018 and revised version accepted 22 May 2018. 


\section{Discussion}

Gestational gigantomastia commonly occurs in multiparous women [1]. Aetiology and pathogenesis of gestational gigantomastia remains largely unknown and there are many hypotheses [2]. A commonly proposed hypothesis is hormonal imbalance or end organ hypersensitivity [1]. However, several cases of gigantomastia have been reported in patients with autoimmune disease like systemic lupus erythematosus, myasthenia gravis and Hashimoto thyroiditis [3]. Medical management has successfully avoided surgery in $40 \%$ of cases [1]. Therefore, trial of medical management should be strongly considered as first line treatment. Bromocriptine produces variable and usually temporary effects $[1,2]$. Agarwal et al. reported that Bromocriptine resulted in healing of the ulcers, resolution of symptoms and marked involution [4]. Use of androgens, estrogens, tamoxifen, dexamethasone, frusemide and prednisone for treatment of gestational gigantomastia have not shown to be successful [5].

Breast reduction or simple mastectomy is an option. Subsequent recurrence and continued hypertrophy of the axillary tails are potential problems following these procedures [6]. Although these complications can lead to maternal and fetal death, no cases of maternal death have been reported since 1920. This case also highlights the need for thromboprophylasix in patients with gestational gigantomastia.
Careful evaluation and multidisciplinary team management are essential to overcome the aesthetic issues, functional impairment and other possible complications when dealing with gestational gigantomastia.

\section{Conflicts of interest}

Authors declare that that there are no conflicts of interest.

\section{References}

1. Swelstad MR, Swelstad BB, Rao VK, Gutowski KA. Management of Gestational Gigantomastia. Plast Reconstr Surg 2006; 118(4): 840-8.

2. Mangla M, Singla D. Gestational Gigantomastia. J Midlife Health 2017; 8(1) 40-4.

3. Le EN, McGrit LY, Abuav R. Gigantomastia and autoimmunity. Lupus 2009; 18: 1015-18.

4. Agarwal N, Kripani A, Gupta A, Bhatta N. Management of Gigantomastia Complicating Pregnancy: A Case Report. $J$ Reprod Med 2002; Med 47: 871.

5. Lafreniere R, Temple W, Ketcham A. Gestational Macromastia. Am J Surg 1984; 148(3): 413-8.

6. Ship AG. Virginal and Gravid Mammary Gigantism Recurrence after reduction mammoplasty. Br J Plast Surg 1971; 24: 396-401. 